\title{
WATER VAPOR TRANSMISSION AND WATERPROOFING PERFORMANCE OF CONCRETE SEALER AND COATING SYSTEMS
}

\author{
Md. SAFIUDDIN ${ }^{\mathrm{a}}$, Khaled A. SOUDKI ${ }^{\mathrm{b}}$ \\ ${ }^{a}$ School of Architectural Studies and Angelo del Zotto School of Construction Management, \\ George Brown College, 146 Kendal Avenue, Toronto, Ontario, Canada M5T 2T9 \\ ${ }^{b}$ Department of Civil and Environmental Engineering, Faculty of Engineering, University of Waterloo, \\ 200 University Avenue West, Waterloo, Ontario, Canada N2L 3G1
}

Received 11 Oct 2012; accepted 04 Feb 2013

\begin{abstract}
This paper reports the water vapor transmission and waterproofing performance of a silane-based penetrating sealer (PS), two cementitious coatings (CC1 and $\mathrm{CC} 2$ ), and a polymeric coating (PC). The sealer and coating products were applied on 100-mm concrete cubes. In total, fifteen concrete cubes including the control specimens were prepared. The treated concrete cubes were tested to determine the ability of the selected products to improve waterproofing and to transmit water vapor. The correlation between water vapor transmission and waterproofing performance was also examined. Experimental results revealed that the cementitious coating $\mathrm{CC} 2$ had the lowest degree of water vapor transmission but the highest degree of waterproofing performance. In contrast, the highest degree of water vapor transmission but the lowest degree of waterproofing performance were observed for the cementitious coating CC1. The penetrating sealer PS provided greater water vapor transmission but lower waterproofing ability than the polymeric coating PC and the cementitious coating $\mathrm{CC} 2$. The best-performing coating with regard to water vapor transmission and waterproofing was the polymeric coating PC. Furthermore, the water vapor transmission and waterproofing performance of the sealer and coating systems were strongly correlated; this suggests that one of these two properties can be predicted by testing the other.
\end{abstract}

Keywords: coating, concrete, sealer, water vapor transmission, waterproofing.

\section{Introduction}

Concrete structures often undergo physical and chemical attacks due to environmental exposures such as wetting and drying, freezing and thawing with or without de-icing salts, and extreme temperature changes (Soudki et al. 2011a). Under such aggressive environmental exposures, concrete structures require special attention to the factors influencing durability, so that they can provide an acceptable service life. Without this consideration, the concrete structures may experience accelerated deterioration such as surface scaling, concrete spalling and cracking, and corrosion of steel reinforcement.

The following protective measures can be adopted to increase the service life of concrete structures (Drochytka, Petranek 2002): 1) improving the physical properties of the concrete and repair materials; 2) altering the electrochemical behavior of steel; and 3) applying surface treatments. Many surface treatments such as sealers, coatings, membranes, and impregnation resins are currently used for the protection of concrete structures (Ibrahim et al. 1999; Palle, Hopwood II 2006; Wenzlick 2007). When sealers and coatings are selected to protect concrete structures, they must have good waterproofing and water vapor transmission properties (Delucchi et al. 1997).

The water penetration into concrete structures due to absorption or permeability is linked with many damage mechanisms that are responsible for concrete deterioration. Li et al. (2012) discussed the influence of water on freezethaw damage in concrete; they showed that when the degree of saturation due to water absorption exceeds $86-88 \%$, the freeze-thaw damage is inevitable with or without entrained air even with very few freeze-thaw cycles. Moreover, water combined with certain deleterious agents such chloride ions and carbon di-oxide causes corrosion of steel reinforcement in concrete structures (Charles et al. 2011; Melchers, Li 2009). Therefore, the penetration of water into concrete must be prevented by any means.

Surface treatments such as sealers and coatings can provide the added protection against the penetration of water. The application of a surface treatment can significantly reduce the water transport into concrete by either rendering the surface region hydrophobic or by forming a physical barrier; some systems combine these two effects by the application of dual-component products (Safiuddin, Soudki 2011). A reduction in water transport into

Corresponding author: Md. Safiuddin

E-mail: msafiuddin@georgebrown.ca 
concrete can improve its freeze-thaw durability (Li et al. 2012; Litvan 1992) and resistance to alkali-aggregate reactions (Filice, Wong 2001). Almusallam et al. (2003) and Moon et al. (2007) observed that surface coatings substantially improved the freeze-thaw resistance of concrete due to reduced water absorption. Ibrahim et al. (1999), Al-Dulaijan et al. (2000), Oshiro and Tanigawa (1988), and Seneviratne et al. (2000) reported that surface coatings significantly decrease reinforcement corrosion in concrete by decreasing the ingress of chloride-laden water. Recently, Medeiros et al. (2012) examined the contributions of the typical concrete surface protection systems such as coatings, linings, and pore blockers through silicate treatment; their results indicated reductions in chloride diffusion coefficients and capillary water absorption from external environmental; in addition, they mentioned that the corrosion kinetics can be controlled through a reduction in the chloride ingress into concrete. Soudki et al. (2012) also observed that sealers and coatings significantly reduced the penetration of water and chloride ions into concrete.

An appropriate surface coating system can protect concrete structures from corrosion and de-icing salt damage by inhibiting the penetration of chloride-laden water (Litvan 1996; Palle, Hopwood II 2006). In contrast, it has been shown that penetrating sealers are not as effective as surface coatings in improving the scaling and corrosion resistances of concrete (Ibrahim et al. 1999; Litvan 1996; Wenzlick 2007). However, the performance of penetrating sealer can be improved by an over-coat application of a surface sealer or coating (Ibrahim et al. 1999). Furthermore, both sealers and coatings must possess good water vapor transmission ability to improve concrete durability. The freeze-thaw damage of the sealed or coated concrete can continue if the water vapor is not transmitted out of the concrete (Soudki et al. 2011b). To reduce this form of damage, a minimum vapor transmission of $35 \%$ (relative to untreated concrete surface) is generally recommended (Rahim et al. 2006).

Significant studies, as stated earlier, have been conducted on the waterproofing performance of concrete sealers and coatings. In comparison, very limited studies investigated their water vapor transmission performance. McCarter (1996) showed that some surface coatings not only restrict the passage of water as a liquid into concrete but also can subsequently facilitate drying by water vapor transmission through the applied coating. Furthermore, Miniotaitè and Stankevičius (2003) reported that the water vapor transmission influences the durability of surface coatings. However, most of the aforementioned studies evaluated the water vapor transmission and waterproofing performance of polymer-based sealer and coating products.

The present study reports the water vapor transmission and waterproofing performance of several commercially available concrete sealer/coating products. Both polymeric and cementitious sealer/coating products were selected in this study to compare their performance. Based on the results of the waterproofing and water vapor transmission performance tests, this study identified the best-performing coating among the selected sealer/coating products. The correlation between waterproofing and water vapor transmission performance was also examined in this study.

\section{Background}

\subsection{Classification of sealers/coatings}

There is no well-known standard classification of sealers and coatings. In Canada, the Alberta Transportation and Utilities (ATU) Department categorizes concrete sealers/ coatings as follows (ATU 2009):

a) Type 1: penetrating sealers. These products are used on traffic bearing concrete surfaces subjected to abrasion, and therefore must not affect the skid resistance of bridge deck or pavement. They are low viscosity materials (for example, silane or siloxane) and achieve a nominal penetration (typically 1 to $3 \mathrm{~mm}$ ) into the prepared concrete substrates. They produce hydrophobic reactions by lining capillary pores, and thus repel water and provide a high degree of "breathability". These products do not change the appearance of the concrete to any significant degree. They may be applied to all exposed concrete surfaces. Type 1a is a sub-classification of penetrating sealers for use on concrete surfaces where the relative moisture content is less than or equal to $55 \%$. Type $1 \mathrm{~b}$ is a sub-classification where the relative moisture content of concrete element is less than or equal to $70 \%$. Type $1 \mathrm{c}$ is a subclassification for high-performance penetrating sealers including low volatile organic compounds; these sealers are used for concretes with low water/cement ratios where the relative moisture content of concrete element is less than or equal to $80 \%$.

b) Type 2: clear film forming sealers. They are also known as surface sealers. These sealers form a film on concrete surfaces and are used on non-traffic bearing surfaces. They are medium viscosity/low solids materials, such as low solids epoxy and urethane and reacted methyl methacrylate, which form films on concrete surfaces; the films are non-measurable and do not penetrate the capillary pores to any degree. They usually have a moderate degree of "breathability". Similar to penetrating sealers, the surface sealers do not change the appearance of concrete to any significant degree. They are not intended to apply on the trafficked surfaces of infrastructures because of their low abrasion resistance. Type 2a is a sub-classification for one-component surface sealers that are suitable for use on concrete surfaces where the relative moisture content of concrete element is less than or equal to $70 \%$. Type $2 \mathrm{~b}$ is a sub-classification for two-component surface sealers where the relative moisture content of concrete element is less than or equal to $70 \%$.

c) Type 3: colored film forming sealers. They are also known as surface coatings. The surface coatings are used on concrete surfaces aesthetically important and highly exposed to public view. They are generally 
high viscosity/high solids pigmented materials, such as acrylic, epoxy and urethane, which form measurable coatings that do not penetrate capillary pores. They typically have low to zero degrees of "breathability". Similar to surface sealers, the use of surface coatings on the trafficked surfaces of infrastructures is generally limited due to their low abrasion resistance.

\subsection{Surface preparation and application of sealers/coatings}

Surface preparation is typically required before the application of a surface treatment. Most manufacturers require that new concrete should be at least 28 days old, and contamination that may interfere with coating adhesion or sealer penetration, such as form oils and curing compounds, should be removed (Attanayaka et al. 2003). For similar reasons, it is a general requirement that oil, grease, rubber and other contaminants should also be removed from old concrete by effective preparation techniques. Most manufacturers recommend abrasiveblasting (sand or grit-blasting), blast-track (shot-blasting) or high pressure water-blasting to prepare the concrete substrate. After preparing the concrete substrate, most manufacturers require a damp, saturated surface-dry or substantially air-dry concrete surface prior to the application of sealers/coatings depending on the specific type of surface treatment.

The preferred methods for the application of sealers/ coatings are typically by roller, airless spray gun, squeegee or brush/broom (Filice, Wong 2001). Attanayaka et al. (2003) reported that the proper application of a penetrating sealer increases its efficiency, stating that surface flooding is the preferred method. Also, Ho and Harrison (1990) reported that the effectiveness of surface coatings improves with the increased thickness of coating.

\subsection{Water vapor transmission and waterproofing performance criteria for sealers/coatings}

The waterproofing and moisture vapor transmission performance criteria that have been established for use in testing different types of concrete sealers and coatings, as described earlier while discussing their classification, are provided in Table 1 and Table 2, respectively.

\section{Materials and methods}

Four different surface treatments were evaluated and compared along with control or untreated concrete (UC). The generic types of the selected sealer and coating products are given in Table 3. The silane-based sealer was used as a penetrating sealer (PS), whereas the acrylicbased polymer coating (PC) and the two cementitious coatings ( $\mathrm{CC} 1$ and $\mathrm{CC} 2)$ were used as surface coatings. According to the manufacturers, the selected coating products provide the desired bond with concrete, and the selected sealer does not affect the bond between concrete and overcoat of most coating materials. The chosen sealer and coating products were applied on the concrete test specimens. In total, fifteen concrete cubes including control specimens were prepared and used to evaluate the water vapor transmission and waterproofing performance of the selected sealer/coating products in accordance with the criteria given in Tables 1 and 2. To facilitate the water vapor transmission and waterproofing performance testing for sealer and coating products, $100-\mathrm{mm}$ cube specimens were prepared by cutting $225 \times 225 \times 100 \mathrm{~mm}$ prisms. Some of the concrete cube specimens are shown in Figure 1.

The prism specimens were cast in the laboratory using ready-mixed concrete. In addition, $\varnothing 100 \times 200 \mathrm{~mm}$ cylinder specimens were cast to examine the compressive strength of concrete. The mix design was selected to represent a typical $35-\mathrm{MPa}$ concrete used in the

Table 1. Water vapor transmission performance criteria for concrete sealers/coatings (ATU 2009)

\begin{tabular}{lc}
\hline Sealer/coating type & $\begin{array}{c}\text { Minimum vapor } \\
\text { transmission (as } \\
\text { compared to control } \\
\text { specimens }\end{array}$ \\
\hline Type $1 \mathrm{a}$ & - \\
\hline Type $1 \mathrm{~b}$ & $70.0 \%$ \\
\hline Type $1 \mathrm{c}$ & $85.0 \%$ \\
\hline Type $2 \mathrm{a}$ & $35.0 \%$ \\
\hline Type $2 \mathrm{~b}$ & $20.0 \%$ \\
\hline Type 3 & $35.0 \%$ \\
\hline
\end{tabular}

${ }^{*}$ Unsealed/uncoated or untreated concrete specimens.

Table 2. Waterproofing performance criteria for concrete sealers/coatings (ATU 2009)

\begin{tabular}{lcc}
\hline \multirow{2}{*}{ Sealer/coating type } & Minimum waterproofing performance (as compared to control specimens $\left.{ }^{*}\right)$ \\
\cline { 2 - 3 } & Before abrasion & After abrasion \\
\hline Type 1a & $82.5 \%$ & $75.0 \%$ \\
\hline Type 1b & - & $86.0 \%$ \\
\hline Type 1c & - & $85.0 \%$ \\
\hline Type 2a & $82.5 \%$ & N/A \\
\hline Type 2b & $90.0 \%$ & N/A \\
\hline Type 3 & $75.0 \%$ & N/A \\
\hline
\end{tabular}

${ }^{*}$ Unsealed/uncoated or untreated concrete specimens. 
Table 3. Different surface treatments and details of test specimens

\begin{tabular}{llc}
\hline Designation & \multicolumn{1}{c}{ Type of surface treatment } & $\begin{array}{c}\text { No. of 100-mm cube } \\
\text { specimens }\end{array}$ \\
\hline $\mathrm{UC}$ & Control or untreated concrete & 3 \\
\hline $\mathrm{PS}$ & A silane-based penetrating sealer including corrosion inhibitor & 3 \\
\hline $\mathrm{PC}$ & A pigmented acrylic-based polymer coating & 3 \\
\hline $\mathrm{CC} 1$ & $\begin{array}{l}\text { A two-component highly flexible and fibre-reinforced cementitious } \\
\text { coating }\end{array}$ & 3 \\
\hline $\mathrm{CC} 2$ & A two-component flexible and polymer-modified cementitious coating & 3 \\
\hline
\end{tabular}

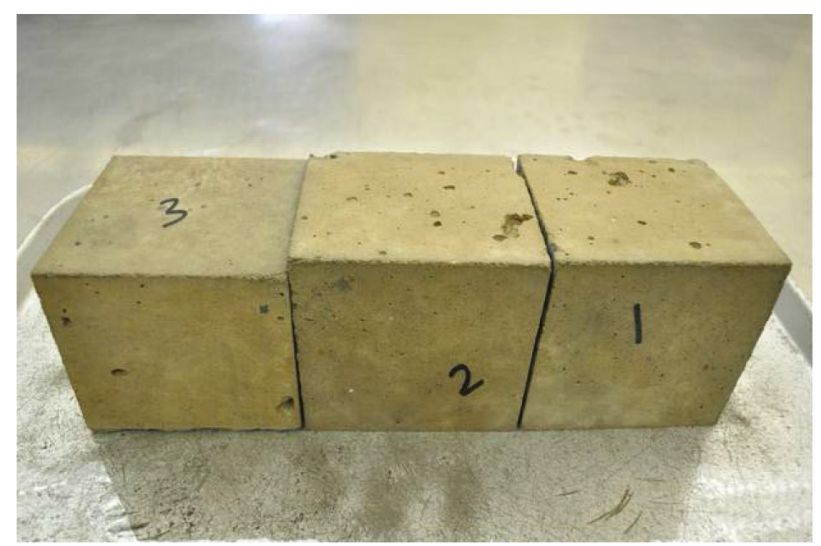

Penetrating (PS) treated concrete cube specimens

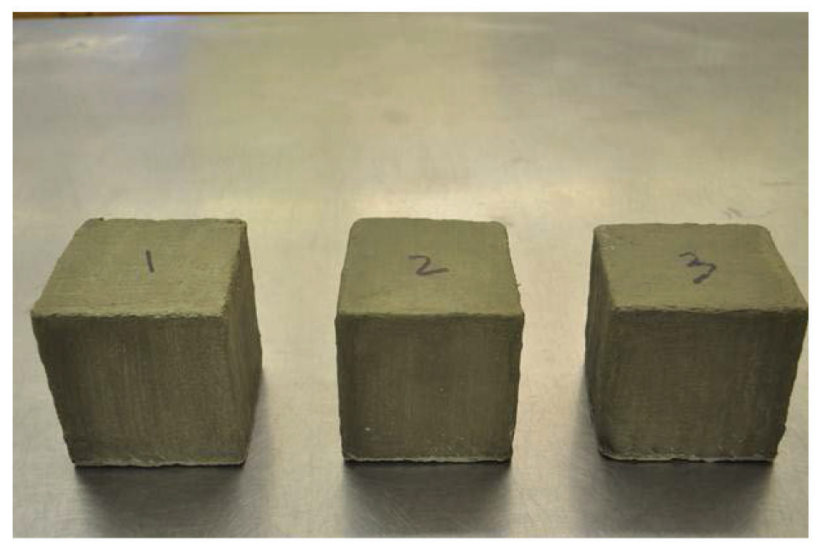

Cementitious coating $1(\mathrm{CC} 1)$ treated concrete cube specimens

Fig. 1. Sealer and coating treated concrete cube specimens

construction of concrete structures. The prism specimens were fabricated using wooden formwork. The cylinder specimens were cast in single-use plastic molds. Both the prism and cylinder specimens were water cured for 7 days by using wet burlap covered with plastic sheet. The cylinder specimens were tested to determine the compressive strength of concrete at 28 days. The 28-day compressive strength of concrete obtained from test was $46.3 \mathrm{MPa}$.

The concrete cube specimens required for waterproofing and water vapor transmission tests were treated

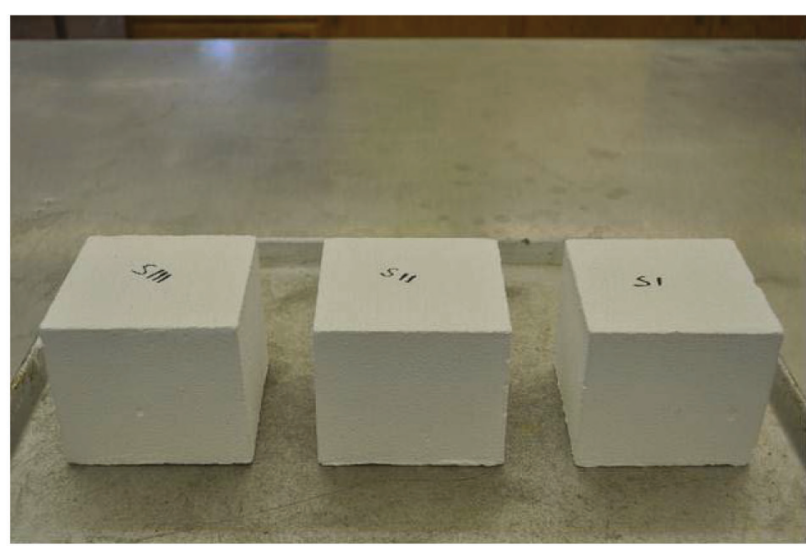

Polymeric coating (PC) treated concrete cube specimens

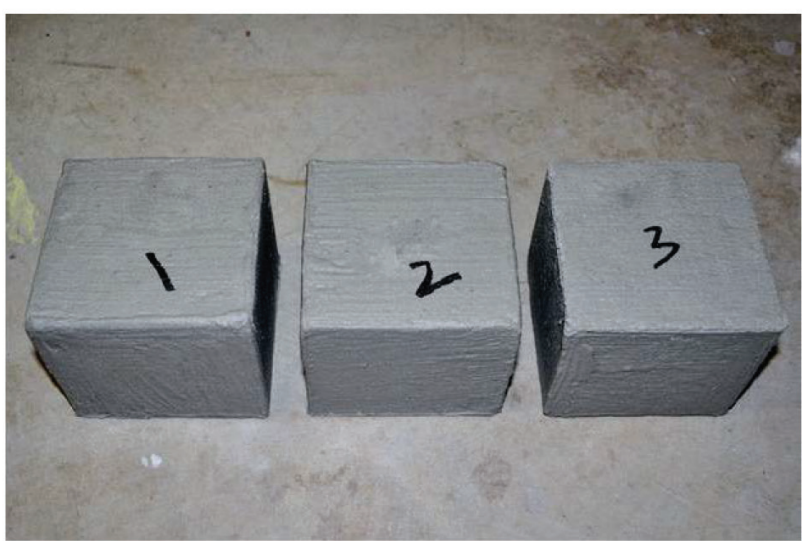

Cementitious coating 2 (CC2) treated concrete cube specimens

with the selected products according to the procedures given by the Alberta Transportation and Utilities in BT001 (ATU 2000). The age of the concrete cubes was 28 days. The specified relative moisture content (70 $\pm 2 \%$ of total moisture content) was achieved before applying the sealer/coating products. The sealer was applied by immersing the concrete cubes in liquid solution of sealer whereas the coatings were applied by brush. The amounts of the sealer and coating products applied on the cubes were determined based on the manufacturer's guidelines. 
The treated and untreated concrete specimens were tested for water vapor transmission and waterproofing performance. The Alberta Transportation and Utilities' test method BT001 (ATU 2000) was used to measure the water vapor transmission and waterproofing performance of the selected sealer and coating products. The cube specimens (control, sealed, and coated) were weighed and placed on a wire shelf for drying. The laboratory drying environment was controlled at $23 \pm 2{ }^{\circ} \mathrm{C}$ and $50 \pm 4 \% \mathrm{RH}$ (relative humidity). The water vapor transmission from the sealed and coated concrete cubes was calculated, and compared with the performance criteria given in Table 1. After completing the water vapor transmission measurements, the same concrete cube specimens were used for the waterproofing performance test. The treated and untreated cube specimens were weighed and then completely immersed in water. The water temperature was maintained at $23 \pm 2{ }^{\circ} \mathrm{C}$. The saturated surface-dry weight of the specimens was taken at the end of the immersion period (typically 5 days). The waterproofing performance of the sealer and coating products was evaluated based on the reduction in water absorption into treated cubes in comparison with control concrete, and compared with the criteria (before abrasion) given in Table 2.

\section{Test results and discussion}

\subsection{Water vapor transmission}

The test results of average mass loss due to water vapor transmission from untreated and treated concrete cubes are provided in Table 4. The water vapor transmission values of different sealer/coating products are presented in Figure 2. These values were obtained based on the water loss of control concrete $(2.60 \mathrm{~g})$. The water vapor transmission of PS sealer was $73.1 \%$. The penetrating sealer PS is categorized under Type $1 \mathrm{~b}$. This penetrating sealer is intended to be used on concrete elements that have a maximum relative moisture content of $70 \%$. The minimum vapor transmission of Type $1 \mathrm{~b}$ penetrating sealer

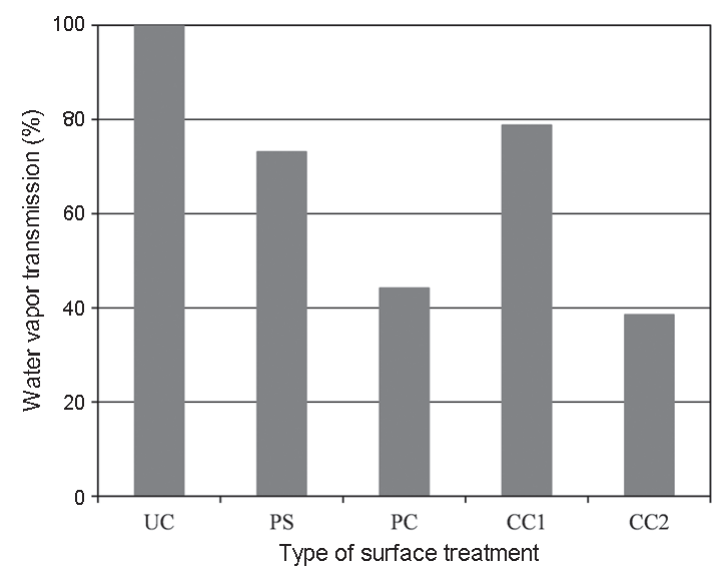

Fig. 2. Water vapor transmission of different surface treatments
Table 4. Water loss in treated and untreated concrete cubes due to vapor transmission

\begin{tabular}{lc}
\hline Type of surface treatment & $\begin{array}{c}\text { Average } \\
\text { water loss } \\
(\mathrm{g})\end{array}$ \\
\hline Untreated concrete (UC) & 2.60 \\
\hline Penetrating sealer $(\mathrm{PS})$ treated concrete & 1.90 \\
\hline Polymer coating (PC) treated concrete & 1.15 \\
\hline Cementitious coating 1 (CC1) treated concrete & 2.05 \\
\hline Cementitious coating 2 (CC2) treated concrete & 1.00 \\
\hline
\end{tabular}

is $70 \%$ (Table 1). Thus, the water vapor transmission of PS sealer fulfilled the minimum requirement for Type $1 \mathrm{~b}$ penetrating sealer.

The water vapor transmission of PC coating was $44.2 \%$. The water vapor transmission of $\mathrm{CC} 1$ and $\mathrm{CC} 2$ coatings was $78.8 \%$ and $38.5 \%$, respectively. According to the Alberta Transportation and Utilities' specification for concrete sealers/coatings, the PC coating conforms to a Type 3 classification, which applies when the colored film forming sealers/coatings are used on concrete elements where the relative moisture content is a maximum of $70 \%$. The minimum water vapor transmission of Type 3 sealers/coatings is $35 \%$ (Table 1 ). The $\mathrm{PC}$ coating greatly fulfilled this requirement. Also, the $\mathrm{CC} 1$ and $\mathrm{CC} 2$ coatings formed color film on concrete surface, and their water vapor transmission was greater than $35 \%$. Hence, both $\mathrm{CC} 1$ and $\mathrm{CC} 2$ coatings can also be classified under Type 3 sealer/coating.

The CC2 coating had the lowest water vapor transmission, as compared to the other sealer and coating products, indicating that this coating possesses a finer pore structure than the other two coatings. It also indicates that this coating might have a lower water absorption property, which indeed was validated from the results of the waterproofing performance test (Fig. 3). The lower water absorption is always conducive to improve durability. However, the lower water vapor transmission may

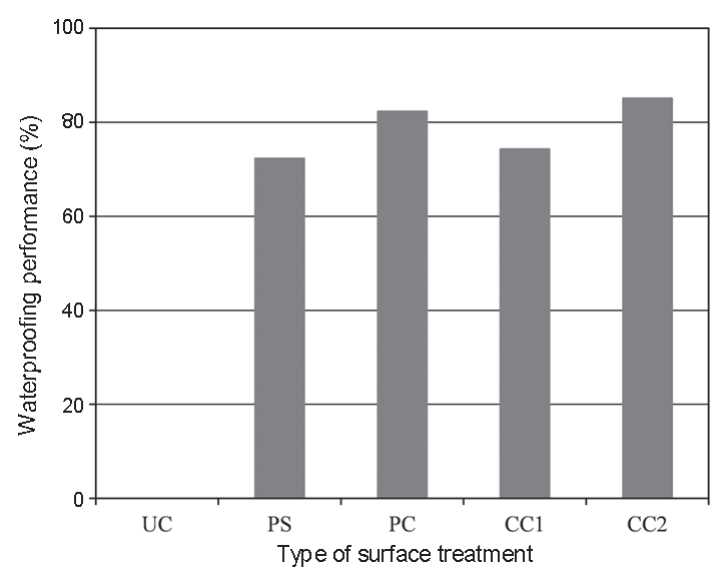

Fig. 3. Waterproofing performance of different surface treatments 
affect the adhesion of coating, and thus its durability under different chemical and environmental conditions, particularly in freezing/thawing environment. This is because water vapor may cause delamination or de-bonding when entrapped under the coating. Hence, a coating should have a reasonably high water vapor transmission property.

\subsection{Waterproofing performance}

The test results of average mass gain due to water absorption in untreated and treated concrete cubes are provided in Table 5. The waterproofing performance values of different sealer/coating products are presented in Figure 3. These values were obtained based on the water gain of control concrete (41.63 g). The waterproofing performance value of PS sealer was $72.3 \%$ and that of PC coating was $82.3 \%$. The waterproofing performance values of $\mathrm{CC} 1$ and $\mathrm{CC} 2$ coatings were $74.3 \%$ and $85.1 \%$, respectively. According to the Alberta Transportation and Utilities' specification for concrete sealers/coatings, the $\mathrm{PC}, \mathrm{CC} 1$ and $\mathrm{CC} 2$ coating conform to a Type 3 classification, as discussed earlier in the case of water vapor transmission results. The minimum waterproofing performance value of Type 3 sealers/coatings is $75 \%$ (Table 2 ). The waterproofing performance values of PC and CC2 coatings were significantly higher than this requirement. The waterproofing performance value of $\mathrm{CC} 1$ coating was very close to $75 \%$. However, the waterproofing performance value of PS sealer was slightly lower than $75 \%$.

\subsection{Overall performance of the selected sealer/coating products}

The cementitious coating CC1 had the highest water vapor transmission ability whereas the cementitious coating CC2 showed the highest waterproofing performance, as compared to the other sealer and coating products (Figs 2 and 3). However, neither the CC1 nor the CC2 was the best-performing coating. This is because the waterproofing performance of $\mathrm{CC} 1$ coating and the water vapor transmission performance of CC2 coating were not relatively good. Both higher water vapor transmission and higher waterproofing performance are desirable for a greater degree of durability. However, waterproofing

Table 5. Water gain in treated and untreated concrete cubes due to absorption

\begin{tabular}{lc}
\hline Type of surface treatment & Average water gain $(\mathrm{g})$ \\
\hline Untreated concrete $(\mathrm{UC})$ & 41.63 \\
\hline $\begin{array}{l}\text { Penetrating sealer (PS) treated } \\
\text { concrete }\end{array}$ & 11.53 \\
\hline $\begin{array}{l}\text { Polymer coating (PC) treated } \\
\text { concrete }\end{array}$ & 7.37 \\
\hline $\begin{array}{l}\text { Cementitious coating 1 (CC1) } \\
\text { treated concrete }\end{array}$ & 10.70 \\
\hline $\begin{array}{l}\text { Cementitious coating 2 (CC2) } \\
\text { treated concrete }\end{array}$ & 6.20 \\
\hline
\end{tabular}

property is more crucial than water vapor transmission for concrete durability; this is because water carries many deleterious agents, which are detrimental for concrete. Based on the results of the moisture vapor transmission and waterproofing performance tests (Figs 2 and 3), the polymeric coating PC was the best-performing coating. In comparison, the penetrating sealer PS exhibited the worst performance.

The overall performance of the selected sealer/coating products can be ranked in the order of $\mathrm{PC}>\mathrm{CC} 2>$ CC1 $>$ PS.

\subsection{Correlation between water vapor transmission and waterproofing performance}

The water vapor transmission and waterproofing performance of the selected sealer and coating products were strongly correlated with a linear relationship, as can be seen from Figure 4. The correlation coefficient (r) was 0.9670 , which suggests an excellent relationship. Moreover, water vapor transmission was inversely correlated with waterproofing performance. This is because the variations in water vapor transmission and waterproofing performance generally followed an opposite trend for different surface treatments. The excellent correlation between waterproofing and water vapor transmission also implies that one of these two properties can be predicted by testing the other.

\section{Conclusions}

This study was carried out to determine the water vapor transmission and waterproofing performance of four sealer/coating products. From the findings of the present study, the following conclusions are drawn:

1) The lowest level of water vapor transmission and the highest level of waterproofing performance were obtained for the cementitious coating CC2. In comparison, the cementitious coating $\mathrm{CC} 1$ had the highest level of water vapor transmission but the lowest level of waterproofing performance among the coating products. Hence, none of them were the bestperforming coating.

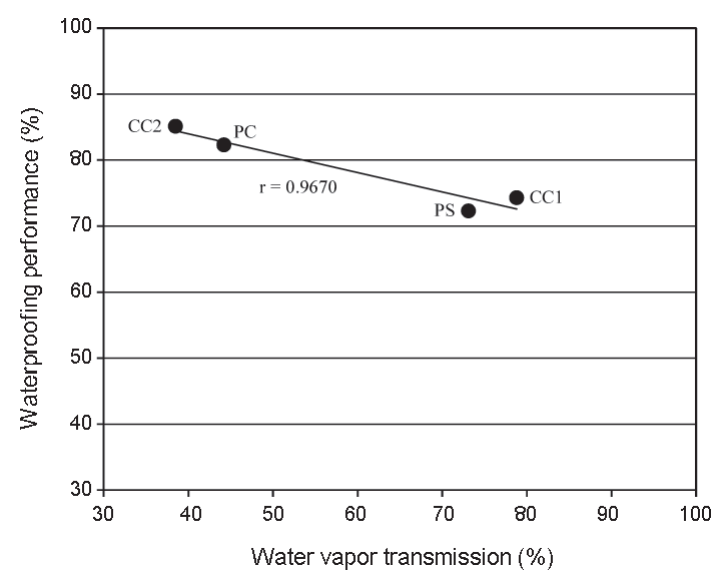

Fig. 4. Correlation between water vapor transmission and waterproofing performance 
2) Among the three different coating products, the bestperforming coating was the acrylic-based polymer coating PC, since its waterproofing performance was significantly high and it possessed relatively good water vapor transmission ability.

3) The worst-performing coating was the cementitious coating $\mathrm{CC} 1$, as this coating showed the lowest waterproofing performance although it possessed the highest water vapor transmission ability. The cementitious coating $\mathrm{CC} 2$ performed much better than the cementitious coating $\mathrm{CC} 1$.

4) The water vapor transmission ability of the penetrating sealer PS was higher than those of the PC and $\mathrm{CC} 2$ coatings but its waterproofing performance was not better than these two coatings. Moreover, the waterproofing as well as water vapor transmission ability of the PS sealer was lower than that of the $\mathrm{CC} 1$ coating.

5) The overall performance of the selected sealer and coating products with respect to water vapor transmission and waterproofing performance can be expressed in the following order from the best to the worst ranking: $\mathrm{PC}>\mathrm{CC} 2>\mathrm{CC} 1>\mathrm{PS}$.

6) The water vapor transmission and waterproofing performance of the sealer and coating products were strongly correlated with an inverse linear relationship; the inverse relationship was observed because water vapor transmission and waterproofing performance mostly varied oppositely for different surface treatments.

7) The strong correlation between water vapor transmission and waterproofing performance indicates that one of these two properties can be predicted by testing the other.

\section{Acknowledgements}

The authors are grateful to BASF Canada, Edco Technologies Inc., and W.R. Meadows of Canada for supplying the sealer/coating products used in the research study.

\section{References}

Al-Dulaijan, S. U.; Maslehuddin, M.; Al-Zahrani, M. M.; Al-Juraifani, E. A.; Al-Idi, S. H.; Al-Mehthel, M. 2000. Performance evaluation of cement-based surface coatings, in Proc. of the ACI Fourth International Conference on Repair, Rehabilitation, and Maintenance of Concrete Structures, and Innovations in Design and Construction (ACI SP-193), September 2000, Seoul, Korea, 321-335.

Almusallam, A. A.; Khan, F. M.; Dulaijan, S. U.; Al-Amoudi, O. S. B. 2003. Effectiveness of surface coatings in improving concrete durability, Cement and Concrete Composites 25(4-5): 473-481. http://dx.doi.org/10.1016/S0958-9465(02)00087-2

Attanayaka, A. M. U. B.; Duyar, O.; Liang, X.; Aktan, H. M.; $\mathrm{Ng}, \mathrm{K}$. Y. S. 2003. Fundamentals of use of penetrating sealants for concrete bridge deck protection, in TRB 2003 Annual Meeting, Paper No. 02-2575. Transportation Research Board (TRB), National Research Council, Washington DC, USA.
ATU. 2000. Test procedure for measuring the vapour transmission, waterproofing and hiding power of concrete sealers (BT001). Technical Standards Branch. Alberta Transportation and Utilities (ATU), Alberta, Canada. $12 \mathrm{p}$.

ATU. 2009. Specification for concrete sealers (B388). Technical Standards Branch. Alberta Transportation and Utilities (ATU), Alberta, Canada.

Charles, S; L'Hostis, V; Poyet, S. 2011. Visual parameters of chloride-induced corrosion of reinforced concrete structures, European Journal of Environmental and Civil Engineering 15(1): 9-24. http://dx.doi.org/10.1080/19648189.2011.9693304

Delucchi, M.; Barbucci, A; Cerisola, G. 1997. Study of the physico-chemical properties of organic coatings for concrete degradation control, Construction and Building Materials 11(7-8): 365-371. http://dx.doi.org/10.1016/S0950-0618(97)00060-3

Drochytka, R.; Petranek, V. 2002. Atmospheric concrete deterioration, in Proc. of the First FIB Conference in Concrete Structures in the 21 $1^{\text {st }}$ Century, 20-24 November 2002, Osaka, Japan, 10-19.

Filice, J.; Wong, J. 2001. Best practice guidelines for selecting concrete bridge deck sealers. Alberta Transportation and Utilities, Alberta, Canada. 6 p.

Ho, D. W. S.; Harrison, R. S. 1990. Influence of surface coatings on carbonation of concrete, Journal of Materials in Civil Engineering ASCE 2(1): 35-44.

http://dx.doi.org/10.1061/(ASCE)0899-1561(1990)2:1(35)

Ibrahim, M.; Al-Gahtani, A. S.; Maslehuddin, M.; Dakhil, F. H. 1999. Use of surface treatment materials to improve concrete durability, Journal of Materials in Civil Engineering ASCE 11(1): 36-40.

http://dx.doi.org/10.1061/(ASCE)0899-1561(1999)11:1(36)

Li, W.; Pour-Ghaz, M.; Castro, J.; Weiss, J. 2012. Water absorption and critical degree of saturation relating to freezethaw damage in concrete pavement joints, Journal of Materials in Civil Engineering 24(3): 299-307. http://dx.doi.org/10.1061/(ASCE)MT.1943-5533.0000383

Litvan, G. G. 1992. The effect of sealers on the freeze-thaw resistance of mortar, Cement and Concrete Resarch 22(6): 1141-1147.

http://dx.doi.org/10.1016/0008-8846(92)90043-U

Litvan, G. G. 1996. Waterproofing of parking garage structures with sealers and membranes: the Canadian experience, Construction and Building Materials 10(1): 95-100. http://dx.doi.org/10.1016/0950-0618(95)00061-5

McCarter, W. J. 1996. Assessing the protective qualities of treated and untreated concrete surfaces under cyclic wetting and drying, Building and Environment 31(6): 551-556. http://dx.doi.org/10.1016/0360-1323(96)00020-0

Medeiros, M.H.F.; Castro-Borges, P.; Aleixo, D. M.; Quarcioni, V.A.; Marcondes, C. G. N.; Helene, P. 2012. Reducing water and chloride penetration through silicate treatments for concrete as a mean to control corrosion kinetics, International Journal of Electrochemical Science 7: 9682-9696.

Melchers, R. E.; Li, C. Q. 2009. Reinforcement corrosion initiation and activation times in concrete structures exposed to severe marine environments, Cement and Concrete Research 39(11): 1068-1076. http://dx.doi.org/10.1016/j.cemconres.2009.07.003

Miniotaite, R.; Stankevicius, V. 2003. The durability of paints on sand-lime brick walls considering water sorption and vapour permeability in a two-layer system, Journal of Civil Engineering and Management 9(2): 110-114. http://dx.doi.org/10.1080/13923730.2003.10531313

Moon, H. Y.; Shin, D. G.; Choi, D. S. 2007. Evaluation of the durability of mortar and concrete applied with inorganic coating material and surface treatment system, Construction 
and Building Materials 21(2): 362-369.

http://dx.doi.org/10.1016/j.conbuildmat.2005.08.012

Oshiro, T.; Tanigawa, S. 1988. Effect of surface coatings on the durability of concrete exposed to marine environment, in Proc. of the Second International Conference on Concrete in Marine Environment, 1988, New Brunswick, Canada, 179-198.

Palle, S.; Hopwood II, T. 2006. Coatings, sealants and fillers to address bridge concrete deterioration and aesthetics phase 1. Research Report No. KTC06-36/SPR 291-04-1F. Kentucky Transportation Center, College of Engineering, University of Kentucky, Lexington, Kentucky, USA.

Rahim, A.; Jansen, D.; Abo-Shadi, N. 2006. Concrete bridge deck crack sealing: an overview of research. Final Report No. F05IR345. Department of Civil and Environmental Engineering, Cal Poly State University, California, USA. 58 p.

Safiuddin, Md.; Soudki, K. A. 2011. Sealer and coating systems for the protection of concrete bridge structures, International Journal of the Physical Sciences 6(37): 8187-8198. http://dx.doi.org/10.5897/IJPSX11.005

Seneviratne, A. M. G.; Sergi, G.; Page, C. L. 2000. Performance characteristics of surface coatings applied to concrete for control of reinforcement corrosion, Construction and Building Materials 14(1): 55-59.

http://dx.doi.org/10.1016/S0950-0618(00)00011-8

Soudki, K. A.; Jeffs, P.; Safiuddin, Md. 2011a. Concrete coating systems on regional bridges: durability performance. Interim Research Report. Department of Civil and Environmental Engineering, Faculty of Engineering, University of Waterloo, Waterloo, Ontario, Canada. 70 p.

Soudki, K. A.; Jeffs, P.; Safiuddin, Md. 2011b. Concrete coating systems on region of Waterloo bridges. Final Research Report. Department of Civil and Environmental Engineering, University of Waterloo, Waterloo, Ontario, Canada.

Soudki, K. A.; Jeffs, P.; Safiuddin, Md. 2012. Chloride penetration resistance of concrete coating systems on region of waterloo bridges. Final Research Report. Department of Civil and Environmental Engineering, Faculty of Engineering, University of Waterloo, Waterloo, Ontario, Canada. $16 \mathrm{p}$.

Wenzlick, J. D. 2007. Bridge deck concrete sealers. Final Research Report RI 04-051. Missouri Department of Transportation, Jefferson City, Missouri, USA.

Md. SAFIUDDIN. Research Associate in the Department of Civil and Environmental Engineering at the University of Waterloo, Ontario, Canada. He is registered as a Professional Engineer (P.Eng.) with Professional Engineers Ontario (PEO). He is a Lifetime Fellow of the Institution of Engineers, Bangladesh and a Member of Bangladesh Environmental Network. His research interests include special concretes, sustainable construction materials, and repair of concrete structures.

Khaled A. SOUDKI. Professor and the Canada Research Chair (Innovative Structural Rehabilitation) in the Department of Civil and Environmental Engineering at the University of Waterloo, Ontario, Canada. He is a P.Eng. Licence holder of Professional Engineers Ontario (PEO). He is a Member of American Concrete Institute Committees 440 (FRP Reinforcement), 222 (Corrosion of Metals) and 546 (Repair). His research interests include corrosion of steel reinforcement, durability of advanced materials, structural health monitoring, and rehabilitation of concrete structures. 